\title{
Climate and the ballot box
}

\section{That democracy will lead to effective action on climate should not be assumed.}

Some climate change 'contrarians' maintain that scientists who warn of dangerous manmade global warming are scaremongering doomsayers. Government spending on environmental protection will, say others, send the economies of rich nations to rack and ruin, while condemning the world's poor to stay that way. Ideologues of a certain ilk believe that salvation will only come through unfettered capitalism and the unbridled forces of the market place, and characterize environmentalists as hopeless romantics who would have us revert to a pre-industrial agrarian existence devoid of life's necessities, such as medicine and flatscreen TVs.

It is in the nature of democracy rightly so - that individuals holding such views should be, and are, free to express their views, mount campaigns, lobby lawmakers and vote for those that share their values and ideals. No one doubts that climate change sceptics, in particular, have been expert at playing the politics game. Whether they have been as good at winning the hearts and minds of the general populace is much less clear (see Snapshot, page 86).

Moreover, they face powerful opposition. In an address last summer, for example, US President Barack Obama called on his fellow Americans concerned about climate change and its impacts to flex their own democratic muscles to help ensure a cleaner, greener future: "Remind everyone who represents you, at every level of government, that there is no contradiction between a sound environment and a strong economy - and that sheltering future generations against the ravages of climate change is a prerequisite for your vote."

Across the world, the political battle lines on climate change and the environment are being drawn. Although a handful of high-profile scientists, such as James Hansen of Columbia University, have campaigned on climate for decades, researchers are entering the realm of political debate and advocacy in increasing numbers. Canada has at least one prominent climate scientist politician, former researcher Andrew Weaver having been elected last year to the Legislative Assembly of British Columbia (N. Jones, Nature Clim. Change 3, 698-699; 2013).

But despite its manifest benefits at least as compared with totalitarian or authoritarian alternatives, past or present - governance based on democratic principles, whether at national level or as enshrined in supranational bodies such as the United Nations, is not guaranteed to deliver decisive, and effective, action on climate. As an example, Australians now have a democratically elected government apparently set on increasing coal production and overturning the carbon tax. More generally, it remains an open question whether national and international governance, as currently formulated, will respond effectively to the challenges of climate change (see Feature, page 81 ).

\section{Icy times}

\section{Weather events make the news but shouldn't be confused with climate change impacts.}

Recent weather events are being discussed in certain circles as proof that climate change is not happening. The 'Polar Vortex' caused Arctic conditions in the United States but this is thought to be an extreme weather event with weak links to climate change (http://go.nature.com/MDd8oA). A number of ships became 'stuck' in Antarctic sea ice this austral summer over the Christmas-New Year holiday period. Social media and the internet were awash with comments on the irony of heavy ice trapping climate change, or global warming, researchers.

We often hear reports of the declining Arctic sea ice cover but much less attention is given to the Antarctic, which, in contrast to the Arctic, has slightly increasing sea ice cover. But why is there such a difference in climate change impacts on the sea ice at the two polar regions? Consider the different environments - the Arctic Ocean is semi-enclosed by land that provides a becalmed sea on which sea ice forms, whereas the Antarctic continent stands alone with sea ice growing from its edges in the circumpolar Southern Ocean. There the sea ice is more easily broken up by winds and waves from the open ocean and is able to drift away from the continent, north into warmer waters. Antarctic winter sea ice covers up to 18 million $\mathrm{km}^{2}$, which shrinks to around 3 million $\mathrm{km}^{2}$ by the end of the summer.

The National Snow and Ice Data Center report that 2013 was above average in sea ice extent - a record, for the satellite era, with the largest winter extent as well as the highest summer minimum. This is on top of a small but increasing trend, $1-4 \%$, in Antarctic sea ice (http://nsidc.org/ arcticseaicenews/, 8 January 2014).

So, was the record ice extent the reason for the ships becoming trapped? Sea ice is a dynamic environment, with winds and ocean currents shifting the ice. Icebergs are an additional hazard to be dealt with. Ships use the best available information to plot a course through this environment, but it can all change very quickly. Katabatic winds, those that flow off the continent to the sea, normally clear the sea ice away from the coast but the wind direction for much of December was from the northeast. This pushed the ice towards the coast in the East Antarctic, where ice flows stacked together to create an impenetrable ice mass.

Working in the polar regions is unpredictable with even the best laid plans at the mercy of the weather. It is essential to our understanding of climate change and its impacts that research is undertaken in this remote and wild region. Hopefully the stranded scientists have gained some valuable data and insights from this experience. 